\title{
Mobile Monitoring for the Spatial and Temporal Assessment of Local Air Quality $\left(\mathrm{NO}_{2}\right)$ in the City of London
}

\author{
Fabio Galatioto ${ }^{1, *(\mathbb{D}}$, James Ferguson-Moore $\left.{ }^{1} \mathbb{(}\right)$ and Ruth Calderwood ${ }^{2}$ \\ 1 Connected Places Catapult, Modelling \& Appraisal, Milton Keynes MK9 1BP, UK; \\ James.Fergusonmoore@cp.catapult.org.uk \\ 2 City of London Corporation, Department of Markets and Consumer Protection, London EC2P 2EJ, UK; \\ ruth.calderwood@cityoflondon.gov.uk \\ * Correspondence: fabio.galatioto@cp.catapult.org.uk
}

check for updates

Citation: Galatioto, F.; Ferguson-Moore, J.; Calderwood, R. Mobile Monitoring for the Spatial and Temporal Assessment of Local Air Quality $\left(\mathrm{NO}_{2}\right)$ in the City of London. Atmosphere 2021, 12, 106. https://doi.org/10.3390/atmos12010106

Received: 7 December 2020 Accepted: 11 January 2021 Published: 13 January 2021

Publisher's Note: MDPI stays neutral with regard to jurisdictional clai$\mathrm{ms}$ in published maps and institutional affiliations.

Copyright: (C) 2021 by the authors. Licensee MDPI, Basel, Switzerland. This article is an open access article distributed under the terms and conditions of the Creative Commons Attribution (CC BY) license (https:// creativecommons.org/licenses/by/ $4.0 /)$.

\begin{abstract}
This paper reports on the analysis and findings of the data collected during a mobile air quality campaign commissioned by the City of London Corporation (CoL). This was done using an equipped vehicle capable of taking continuous precision measurements of local air quality while travelling within the City. Several comparative analyses on measured Nitrogen Dioxide $\left(\mathrm{NO}_{2}\right)$ data have been performed between Smogmobile data and those available from CoL precision systems as well as with indicative systems, namely Diffusion Tubes, distributed across the City. Key findings highlight that data collected from the Smogmobile, in terms of average concentration of $\mathrm{NO}_{2}$ across the City $\left(62 \mu \mathrm{g} / \mathrm{m}^{3}\right)$, are very similar to those obtained by averaging the values from the 48 indicative systems $\left(59.5 \mu \mathrm{g} / \mathrm{m}^{3}\right)$, with an error of just $4 \%$. Overall, this study demonstrates significant potential and value in using mobile air quality measurements to support assessment of air quality over large areas by Local authorities.
\end{abstract}

Keywords: mobile Monitoring; statistical analysis; Smogmobile; Nitrogen Dioxide; precision systems; large areas

\section{Introduction}

The current fixed station monitoring does not provide spatial variations of the pollutant concentrations across a city and tends to underestimate personal exposure, as it does not take into account all locations and activities which contribute to an individual's exposure [1,2]. The air quality information across these stations is not representative of the air quality at hot spots, i.e., traffic congestion and street canyons, etc. Therefore, the current stationary monitoring network is not useful for personal exposure assessment and health risk analysis. In addition, the number of monitoring stations in a city is also limited due to their high capital and operating costs, i.e., the costs to set up fixed site monitoring stations using sophisticated instrumentation are substantial.

Moreover, while outdoor fixed monitoring can provide better information about the air quality, the high level of installation (often around $3 \mathrm{~m}$ altitude) does not reflect a true impact of the pollution at the human level. More recent studies have started to explore not only fixed outdoors sensing units, but also mobile sensors which can be carried by hand, installed on cars/etc. For example, a recent study [3] used a smart personal air quality system carried by pedestrians walking on predefined paths or by bus in different locations in India; the analysis revealed non-linear relations between the gaseous pollutant concentrations versus the resistance offered by different sensors; there was not, however, any data-driven modelling or predictions of the pollutants being measured. A similar direction was taken by [4], who used portable sensors for measuring $\mathrm{NO}_{2}$ concentrations in Montreal carried by pedestrians walking or biking; the authors applied statistical and land-use regressions for data modelling which revealed sensitivity to the number of road segments and the number of visits per segment. Other studies presented in $[5,6]$ deployed 
similar mobile sensors near to the breathing level, but there was no data-driven modelling attached to the results, except from visual data representation.

More recent studies and applications have implemented alternative approaches such as in [7]; Google Street Cars have been equipped with Air Pollution monitors for mobile monitoring and process the data for machine learning modelling applications, while [8] and [3] in 2019 applied similar concepts of mobile monitoring campaigns using multiple low-cost sensors across five routes during a three-week period in Seoul and Chennai City, respectively, suggesting that similar mobile sampling together with 'open data' sources could be applied to generate and construct Land use regression (LUR) models and maps with fine spatial granularity, and machine learning methods could further improve model performance. The latest applications published are from [9] in 2020, developing programmes of mobile monitoring on bicycle to enhance the spatial and temporal modelling capabilities.

Therefore, there is an immediate requirement to complement existing air quality monitoring networks with flexible and affordable alternative technologies and monitoring methods to improve spatial and temporal resolution of air quality data for both scientific and public awareness purposes [10]. As [11] described, it is not crucial to obtain the same level of accuracy of reference instruments for different monitoring objectives.

In this study, the use of mobile air quality data has been chosen to demonstrate that mobile monitoring can also provide multiple benefits to both local authorities and researchers in better understanding of the spatial and temporal distribution of air quality, to enable Local Authorities to assess air quality over larger areas. When integrated with other data sources, such as street-level population and traffic dynamics data, mobile air quality data could also be used to assess population exposure to short- and long-term concentrations of air pollution in the City of London and potentially other urban centres where local air quality is poor and pollution exposure needs to be reduced.

\section{Experiments}

For the scope of this study, several comparative analyses on measured $\mathrm{NO}_{2}$ data have been performed by the Connected Places Catapult (CPC). Specifically, comparisons between Smogmobile data and those available from three Local Authority precision systems, namely, Continuous Monitoring Stations (CMS), were carried out alongside comparison with almost 50 indicative systems, namely, Diffusion Tubes (DT), distributed across the same area of the city highway network.

The overall aim of the project was to assess in a preliminary study the validity of the Smogmobile data in terms of how they compare to locally measured and calibrated $\mathrm{NO}_{2}$ data.

Nitrogen dioxide is a brown gas, with the chemical formula $\mathrm{NO}_{2}$. It is chemically related to nitric oxide (nitrogen monoxide), a colourless gas with the chemical formula NO. Together, $\mathrm{NO}$ and $\mathrm{NO}_{2}$ are known as $\mathrm{NO}_{\mathrm{x}}$. $\mathrm{NO}_{\mathrm{x}}$ is produced when fossil fuels (coal, natural gas, petrol or diesel in a car engine, or natural gas in a domestic central heating boiler or power station) are burned. With respect to $\mathrm{NO}_{\mathrm{x}}, \mathrm{NO}_{2}$ in particular can affect our health; in fact, there is evidence that high levels of it can inflame the airways in our lungs and, over a long period of time, affect how well our lungs work. People with asthma are particularly affected. $\mathrm{NO}_{2}$ can also affect vegetation. Road transport is the second largest source of $\mathrm{NO}_{\mathrm{x}}$ emissions in the UK, contributing 34\% of total emissions in 2019 [12].

The objective of the CoL authority was that through the evidence from this initial study, this could open up further opportunities to consider its more regular use in undertaking air quality assessment over larger areas. The method of analysis followed a three-step process:

1. Data acquisition, cleaning and preparation; this included acquisition of both Smogmobile and Local Authority air quality data. Identification of gaps and errors and classification of the Smogmobile data in terms of static and dynamic (depending on whether the vehicle was stationary or moving).

2. Spatial analysis of the Smogmobile data based on density plots (both at grid level and proximity distance from Local Authority monitoring systems (CMS and DT)). 
3. Statistical analysis of the result of the spatial outputs and assessment of the suitability of the dynamic monitoring system to provide useful insights for Local Authorities and to widely consider monitoring air quality in urban areas and to assess over time the impacts of strategies at a finer resolution.

\subsection{Case Study}

This study used the data collected during a monitoring activity that took place over a five-day period in March 2017 by EnviroTechnology for the City of London Corporation [13]. For this preliminary study, as the Smogmobile travelled around the City of London road network, time and location (latitude and longitude) data were logged and averaged at oneminute intervals, along with pollutant concentration data and wind speed and direction data. The Smogmobile (Figure 1) is based on a Nissan e-NV-200 electric van, and therefore produces no exhaust emissions of its own which could influence measurements. The vehicle is equipped with a variety of instrumentation to measure gas and particulate air pollution Sample air is fed into the gas analysers via a manifold, which is connected to a switching valve that allows switching between outside (ambient) and inside (inside the cab of the vehicle) sampling modes, and at external roof and kerbside positions. $\mathrm{NO}_{2}$ concentrations were measured using a precision Teledyne-API T500U analyser, which uses an optical technique to measure $\mathrm{NO}_{2}$ directly. Unlike conventional chemi-luminescence based $\mathrm{NO}_{x}$ instruments, the $\mathrm{T} 500 \mathrm{U}$ measures $\mathrm{NO}_{2}$ directly using an optical technique known as cavity-attenuated phase-shift spectroscopy (CAPS). This technique has several advantages over chemiluminescence-based instruments using heated molybdenum converters, such as reduced power consumption, faster response, and greatly reduced susceptibility to false $\mathrm{NO}_{2}$ measurements caused by other nitrogen-containing compounds such as nitrous acid (HONO) and peroxyacyl nitrates (PAN). The T500U is a US-EPA certified equivalent method, and has been granted UK MCERTS certification. The T500U features a lower detectable limit with a precision of $\pm 0.5 \%$ (above $5 \mathrm{ppb}$ ).

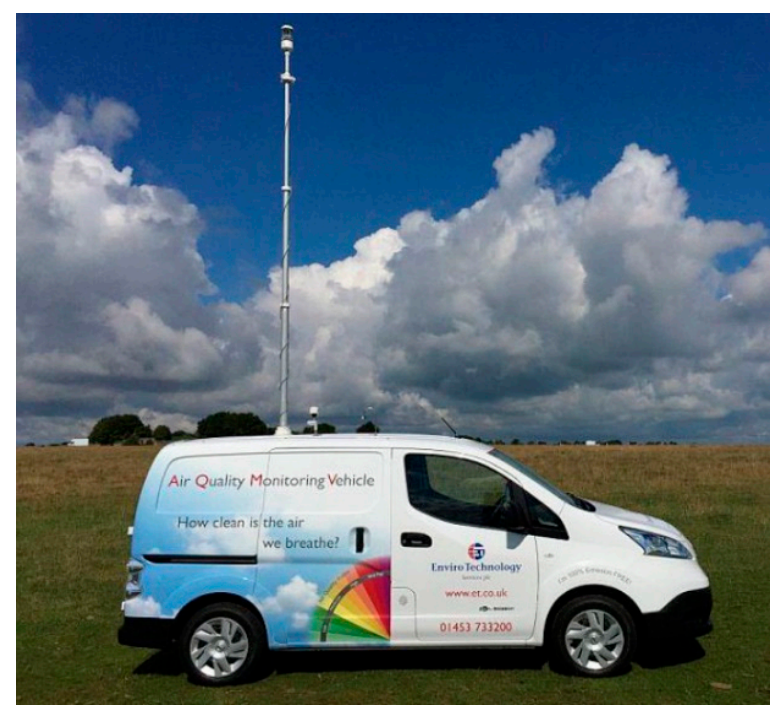

Figure 1. Enviro Technology air quality monitoring vehicle (Smogmobile, source [13]).

Table 1 presents the time and location log of the five-day survey, noting when and where the Smogmobile was stationary and the associated sampling mode (inside, outside, roof, kerbside). For most of the working day (all measurements took place between the hours of 06:00 and 18:00). The Smogmobile was out on the City of London road network logging pollutant concentrations. However, it was also stationary for varying periods of time at particular locations in the City (a sample is given in Table 1). 
Table 1. Example of a one-day Smogmobile Air Quality measurement Time and Location record.

\begin{tabular}{|c|c|c|c|c|c|c|}
\hline Date & Day & Location & Start Time & End Time & Duration & Sampling Mode \\
\hline \multirow[t]{10}{*}{ 23/March/2017 } & Thursday & Walbrook Wharf Carpark & 07:07 & - & N.A. & N.A. \\
\hline & & Fann Street & $08: 23$ & 08:57 & $00: 34$ & Outside, Roof \\
\hline & & Appold Street & 09:47 & 09:50 & 00:03 & \\
\hline & & Guildhall Library & $10: 16$ & $10: 49$ & $00: 33$ & \\
\hline & & Walbrook Wharf Carpark & $11: 20$ & $13: 14$ & 01:54 & Outside, Roof \\
\hline & & St Bartholomew's Hospital & $14: 04$ & $16: 10$ & 02:06 & Outside, Roof \\
\hline & & Fann Street & $16: 17$ & $16: 25$ & 00:08 & Outside, Roof \& Kerb \\
\hline & & Milton Street & $16: 28$ & $16: 39$ & 00:11 & \\
\hline & & St Katharine's Way & $17: 17$ & $17: 43$ & $00: 26$ & \\
\hline & & Walbrook Wharf Carpark & - & $18: 16$ & N.A. & N.A. \\
\hline
\end{tabular}

The daily monitoring activities of the Smogmobile did start and end at the same location, namely, Walbrook Wharf car park (near the CoL office). However, during the lunch breaks, the Smogmobile did return to the same car park for several hours to enable the driver to rest and to recharge system batteries. Overall, the speed of the Smogmobile vehicle was not particularly high, $<25 \mathrm{~km} / \mathrm{h}$ for the majority of the running time, meaning that outside stationary conditions nearby precision monitoring stations and during lunch breaks, the measurements would not overlap more than $2(200 \mathrm{~m})$ cells, making it acceptable for the CoL, the grid approach described in Section 3.

For this study, all Smogmobile data captured outside of the five-day survey period were excluded from the analysis. The Smogmobile data were provided directly to the CPC by the CoL in MS Excel format and were subsequently plotted in a Geographical Information System (ArcGIS) for further analysis. For more detailed information regarding the Smogmobile measurement technology and the March 2017 survey, the reader is referred to the original ETS assessment report (Enviro Technology, 2017).

\subsection{Continous and Indicative Monitoring}

In 2017, the $\mathrm{CoL}$ undertook continuous monitoring of $\mathrm{NO}_{2}$ at three $\mathrm{CMS}$ locations [13] identified in Figure 2 with the code CT:

- CT3: Sir John Cass School (east section of the City, near to Aldgate);

- CT4: Beech Street (north section of the City, within a road tunnel, near the Barbican estate); and,

- CT6: Walbrook Wharf (south section of City, near Cannon Street Station and the River Thames).

Calibrated and ratified $\mathrm{NO}_{2}$ concentrations as measured in March 2017 and the 2017 annual mean at CT3, CT4, and CT6 sites are presented below in Table 2. Annual mean concentrations of $\mathrm{NO}_{2}$ were significantly above the annual mean limit value of $40 \mu \mathrm{g} / \mathrm{m}^{3}$ at CT4 $\left(81 \mu \mathrm{g} / \mathrm{m}^{3}\right)$ and CT6 $\left(93 \mu \mathrm{g} / \mathrm{m}^{3}\right)$, and only marginally below the annual limit value at the urban background site, Sir John Cass School, CT3 $\left(38 \mu \mathrm{g} / \mathrm{m}^{3}\right)$. Although not directly comparable with the annual mean limit value, $\mathrm{NO}_{2}$ concentrations at all three CMS were higher than $40 \mu \mathrm{g} / \mathrm{m}^{3}$ in March 2017.

Figure 2 presents the CMS locations and shows the high spatial distribution of the diffusion tubes across the CoL administrative area. Further, for two CMS locations (CT3 and CT6), several diffusion tubes are located in close proximity, providing a good basis for comparison between the three monitoring systems (Smogmobile, CMS, and DT).

According to data supplied by the CoL, indicative diffusion tube monitoring was undertaken at 77 locations across the City in 2017 (see Figure 2 for locations). Of the 77 diffusion tube sites, 29 locations had no data recorded for the March 2017 period. Annual mean concentrations of $\mathrm{NO}_{2}$ were at, or above, the annual mean limit value of $40 \mathrm{\mu g} / \mathrm{m}^{3}$ at 69 of the $77(90 \%)$ diffusion tube sites in 2017. Although not directly comparable with the annual mean limit value, concentrations of $\mathrm{NO}_{2}$ were higher than $40 \mu \mathrm{g} / \mathrm{m}^{3}$ at 42 of 48 (87.5\%) diffusion tube sites in March 2017. Both reference and indicative pollution measurements provided and used in this study were certified and produced by calibrated 
instrumentation from the Local Authority. Similarly, the instruments used within the Smogmobile were fully calibrated and of the same type used in standard air quality monitoring stations.

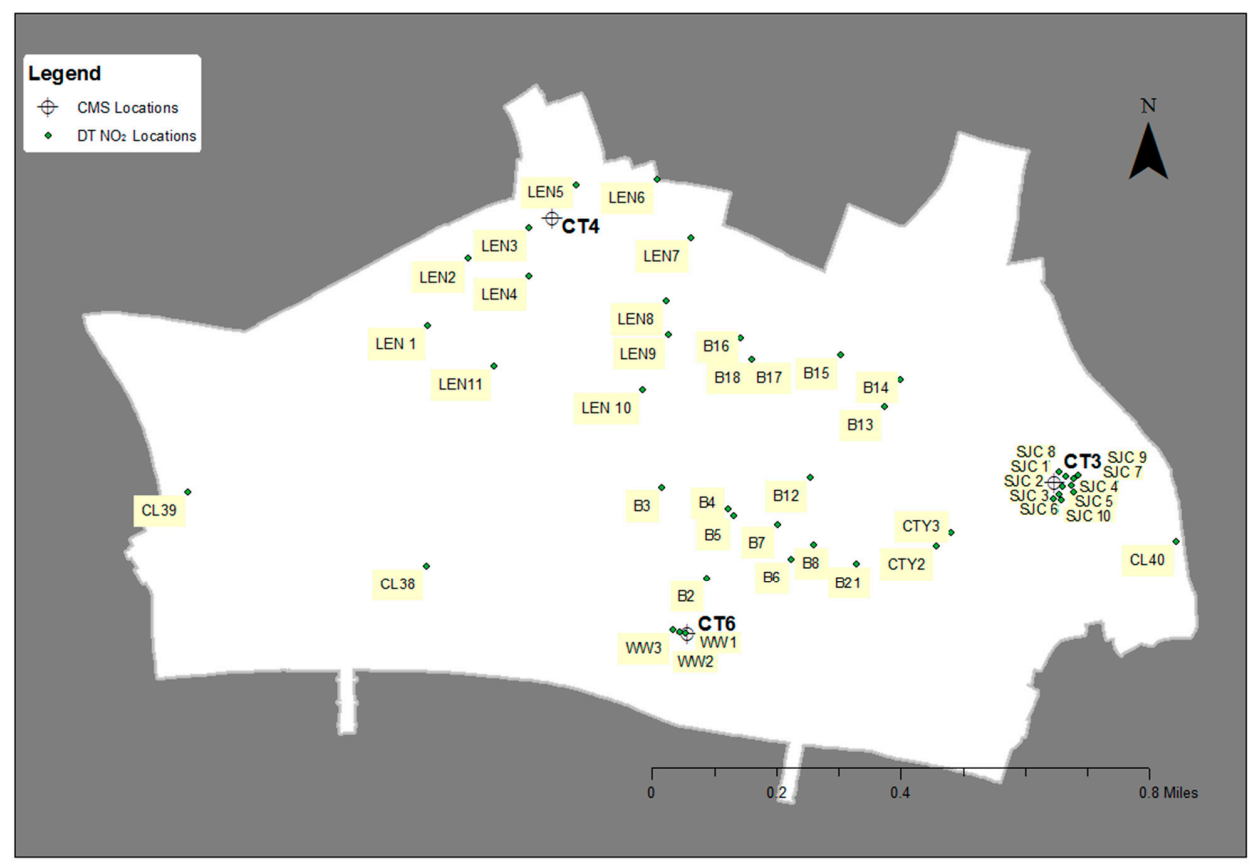

Figure 2. City of London CMS and Diffusion Tube locations.

Table 2. CoL CMS NO 2 concentrations $\left(\mu \mathrm{g} / \mathrm{m}^{3}\right), 2017$.

\begin{tabular}{|c|c|c|c|c|c|c|}
\hline Site ID * & Site Type * & Easting $(X) *$ & Northing $(\mathrm{Y})$ * & $\begin{array}{c}2017 \text { Annual } \\
\text { Mean }\left(\mu \mathrm{g} / \mathrm{m}^{3}\right) \text { * }\end{array}$ & $\begin{array}{l}\text { (March } 2017 \\
\text { Mean) } * *\end{array}$ & $\begin{array}{c}\text { Data Capture } \\
(\%) * *\end{array}$ \\
\hline $\begin{array}{c}\text { CT3 (Sir John Cass } \\
\text { School) }\end{array}$ & $\begin{array}{c}\text { Urban } \\
\text { Background }\end{array}$ & 533,475 & 181,187 & 38 & 42 & $98,(98)$ \\
\hline CT4 (Beech Street) & Roadside & 532,176 & 181,862 & 81 & 82 & $99,(98)$ \\
\hline CT6 (Walbrook Wharf) & Roadside & 532,528 & 180,784 & 93 & 113 & $97,(98)$ \\
\hline
\end{tabular}

${ }^{*}$ For CT4 and CT6, the CoL Air Quality Annual Status Report for 2017 states 80 and $92 \mu \mathrm{g} / \mathrm{m}^{3}$, respectively. The values of 81 and $93 \mu \mathrm{g} / \mathrm{m}^{3}$ presented in Table 2 are calculated from data obtained from the London Air Quality Network (LAQN) (https://londonair.org. uk/LondonAir/Default.aspx). ${ }^{* *}$ March 2017 CMS data obtained from the LAQN.

\section{Results}

\subsection{Spatial Density Analysis}

To characterise the spatial density of the Smogmobile $\mathrm{NO}_{2}$ measurements, ArcGIS was used to define two different grid resolutions (100 m and $200 \mathrm{~m}$ grid square networks) within an 'Area of Interest' (grey area in Figures below) covering the City of London and immediate environs. The average $\mathrm{NO}_{2}$ concentration measured by the Smogmobile was adopted for the entire road line between two consecutive points. Each line between two points could overlap with one or more grid square; hence, depending on the grid resolution adopted, the average $\mathrm{NO}_{2}$ concentration was assigned to each of the grid/s square/s, and then an average was calculated among all values (or Smogmobile data points) falling within that grid square. In this study, that was the best approximation possible; however, in a subsequent study, the data measurements will be performed at a higher resolution (sec-by-sec) eliminating the problem of each measurement representing an average concentration among multiple grid squares.

The output of the density plotting process is presented below in Figures 3 and 4 for $100 \mathrm{~m}$ and $200 \mathrm{~m}$ grid square networks, respectively. White areas within the City of 
London boundary indicate that there were no Smogmobile data for that location/grid square. Numbers within each grid cell indicate the number of samples used to calculate the average pollution concentration levels. This analysis indicates that average NO2 concentrations measured by the Smogmobile were generally higher in the south of the City, where high volume traffic and the presence of busier junctions (roundabouts and signalised) produce higher emissions leading, for the most part, to values higher than $40 \mu \mathrm{g} / \mathrm{m}^{3}$ (the annual limit value) across the extent of the City.

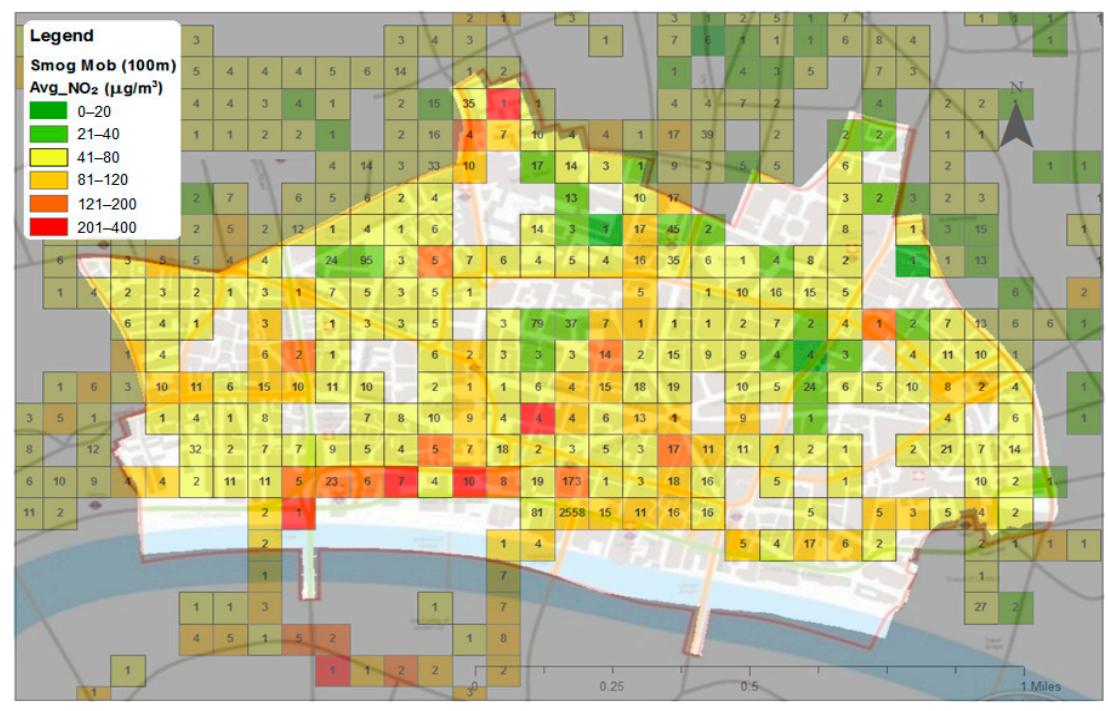

Figure 3. Smogmobile Density Plot (100 m grid resolution) with overlaying background of major roads.

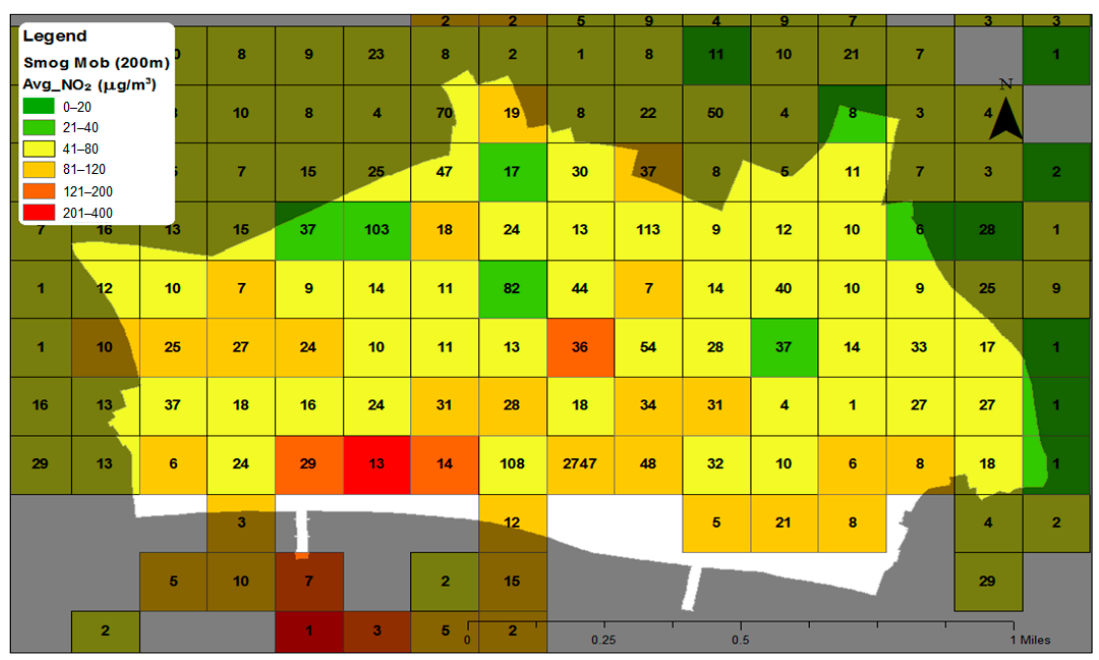

Figure 4. Smogmobile Density Plot (200 m grid resolution).

Further, some of the highest concentrations were recorded inside the road tunnel in Upper Thames St. (A3211) due to scarce ventilation.

Both Figures 3 and 4 indicate that only an area covering approximately six $200 \mathrm{~m} \times 200 \mathrm{~m}$ grid squares (or twenty-four $100 \mathrm{~m} \times 100 \mathrm{~m}$ grid squares) within the City boundary experienced average $\mathrm{NO}_{2}$ concentrations of less than or equal to $40 \mu \mathrm{g} / \mathrm{m}^{3}$. This is equivalent to an area of approximately $0.24 \mathrm{~km}^{2}, 7.62 \%$ of the entire area within the CoL boundary $\left(3.15 \mathrm{~km}^{2}\right)$.

\subsection{Time Series Analysis}

Figure 5 presents, at 15 -minute intervals (Cumulative average is calculated starting from 1 January; when adding a new record, the average is re-calculated based on all 
of the measurements/data points.), cumulative average $\mathrm{NO}_{2}$ concentrations in 2017 at CT3 (Sir John Cass School), CT4 (Beech Street), and CT6 (Walbrook Wharf), along with corresponding monthly average $\mathrm{NO}_{2}$ concentrations from the diffusion tubes (expressed as the unadjusted average of all $\mathrm{NO}_{2}$ diffusion tube measurements in each month).

\section{Annual Average}

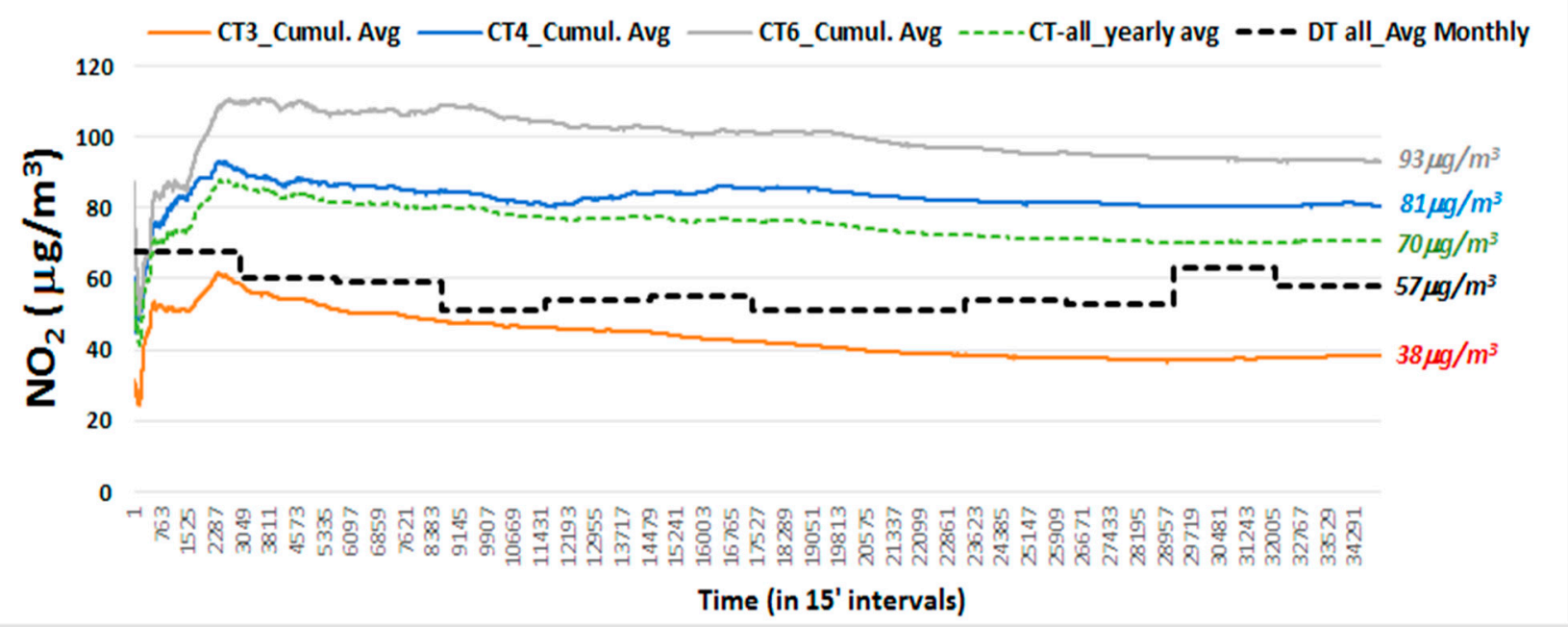

Figure 5. Cumulative average $\mathrm{NO}_{2}$ concentrations $\left(\mu \mathrm{g} / \mathrm{m}^{3}\right)$ at CoL CMS and Diffusion Tube Sites (2017 Calendar Year).

The CMS data indicate that (following an initial period of measurement instability at the start of the calendar year) after between four and six months of monitoring activity, $\mathrm{NO}_{2}$ concentrations stabilise to approximately match the final annual mean concentration at the end of the year.

The final average $\mathrm{NO}_{2}$ concentration of all three CMS $\left(70 \mu \mathrm{g} / \mathrm{m}^{3}\right)$ is closer to the final annual mean $\mathrm{NO}_{2}$ concentration derived from the monthly diffusion tube measurements $\left(57 \mu \mathrm{g} / \mathrm{m}^{3}\right.$, unadjusted) than any of the individually derived annual average values for CT3, CT4, and CT6, and is within $\pm 25 \%$ (according to DEFRA's Technical Guidance) LAQM.TG(09) states that diffusion tube measurement uncertainty is often cited as being $\pm 25 \%$ of the final annual mean diffusion tube concentration $\left(57 \mu \mathrm{g} / \mathrm{m}^{3}, 55 \mu \mathrm{g} / \mathrm{m}^{3}\right.$ bias adjusted $)$.

Figure 6 below presents the same annual cumulative average as per Figure 5, but includes also the cumulative average $\mathrm{NO}_{2}$ concentration for each CMS when considering the date and time matching the available Smogmobile data (labelled 'week_cumul.avg' later in Figure 8) during the survey period in March 2017. This means that several overnight periods and some periods when the Smogmobile was not monitoring or was not on-street have been excluded from the average.

CT3 and CT4 show a reasonable correlation between the 5-day and annual average, while CT6 $\left(132 \mu \mathrm{g} / \mathrm{m}^{3}\right)$ and all CMS $\left(86 \mu \mathrm{g} / \mathrm{m}^{3}\right)$ are less well correlated with only CT6 falling outside $\pm 25 \%$ of the corresponding annual mean values $\left(93 \mu \mathrm{g} / \mathrm{m}^{3}\right.$ and $70 \mu \mathrm{g} / \mathrm{m}^{3}$, respectively). 


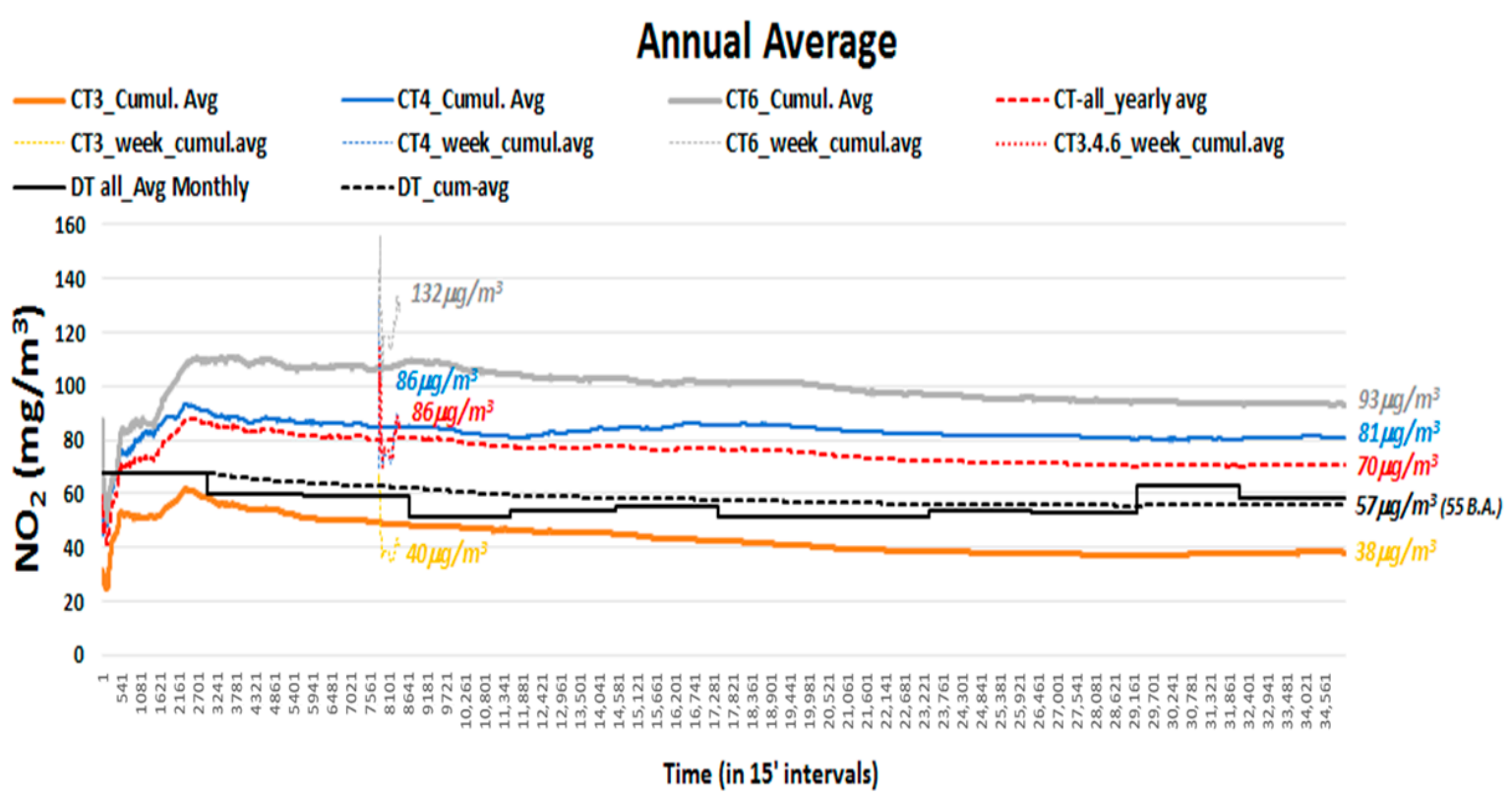

Figure 6. Cumulative average $\mathrm{NO}_{2}$ Concentrations $\left(\mu \mathrm{g} / \mathrm{m}^{3}\right.$ ) at CoL CMS and Diffusion Tube Sites (2017 Calendar Year and Survey Period (Excluding times when the Smogmobile was not operating, e.g., overnight stays in car parks and during lunch breaks.).

Figure 7 shows the cumulative average for each of the three CMS (and the average of all three CMS) during the entire Smogmobile Survey period (from 7:30 a.m. on the 23 March 2017 until 13:00 on the 29 March 2017). Average values for CT3, CT4, CT6, and all CTs are $38 \mu \mathrm{g} / \mathrm{m}^{3}, 82 \mu \mathrm{g} / \mathrm{m}^{3}, 116 \mu \mathrm{g} / \mathrm{m}^{3}$ and $78 \mu \mathrm{g} / \mathrm{m}^{3}$, respectively, consistently higher than those in Figure 9, between 5\% and 12\%.

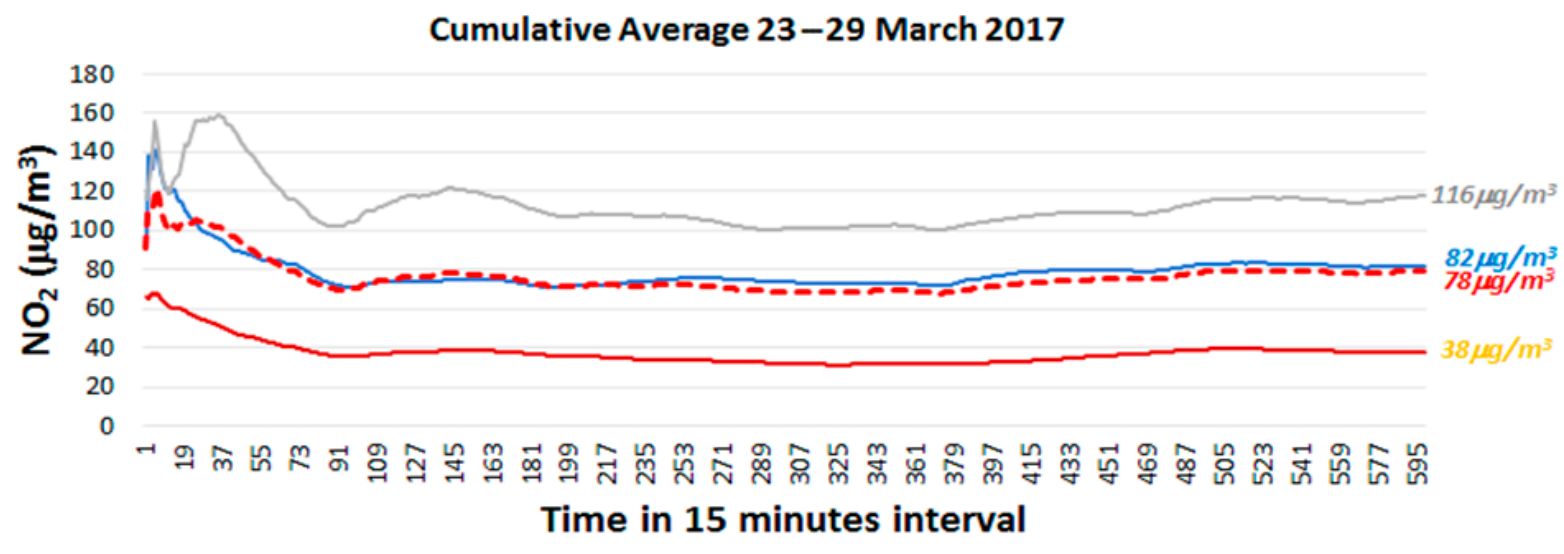

СТ3 weekly avg _ CT4 weekly avg_CT6 weekly avg _- - All CTs weekly avg

Figure 7. Cumulative average $\mathrm{NO}_{2}$ Concentrations $\left(\mu \mathrm{g} / \mathrm{m}^{3}\right)$ at CoL CMS for the full Smogmobile Survey Period.

This provides evidence that it is really important to design and plan in advance the time and location where a mobile monitoring system should operate to avoid observing or measuring concentration and in particular obtain averages that may not be representative of the real situation and the annual mean. In this case, excluding overnight observations has the impact to return averages that are generally higher (5 to $12 \%$ ) than those normally observed by continuous monitoring systems located on the street.

Figures 8 and 9 present, for the five-day Smogmobile survey period, cumulative average $\mathrm{NO}_{2}$ concentrations for all three CMS (expressed as the cumulative average of the $\mathrm{NO}_{2}$ concentrations measured at CT3, CT4, and CT6), all diffusion tubes (expressed 
as the average $\mathrm{NO}_{2}$ concentration measured from all diffusion tubes in March 2017), and the Smogmobile (expressed as the cumulative average of all $\mathrm{NO}_{2}$ concentrations measured by the Smogmobile) without stationary car park measurements (Figure 9) and with all measurements (Figure 8).

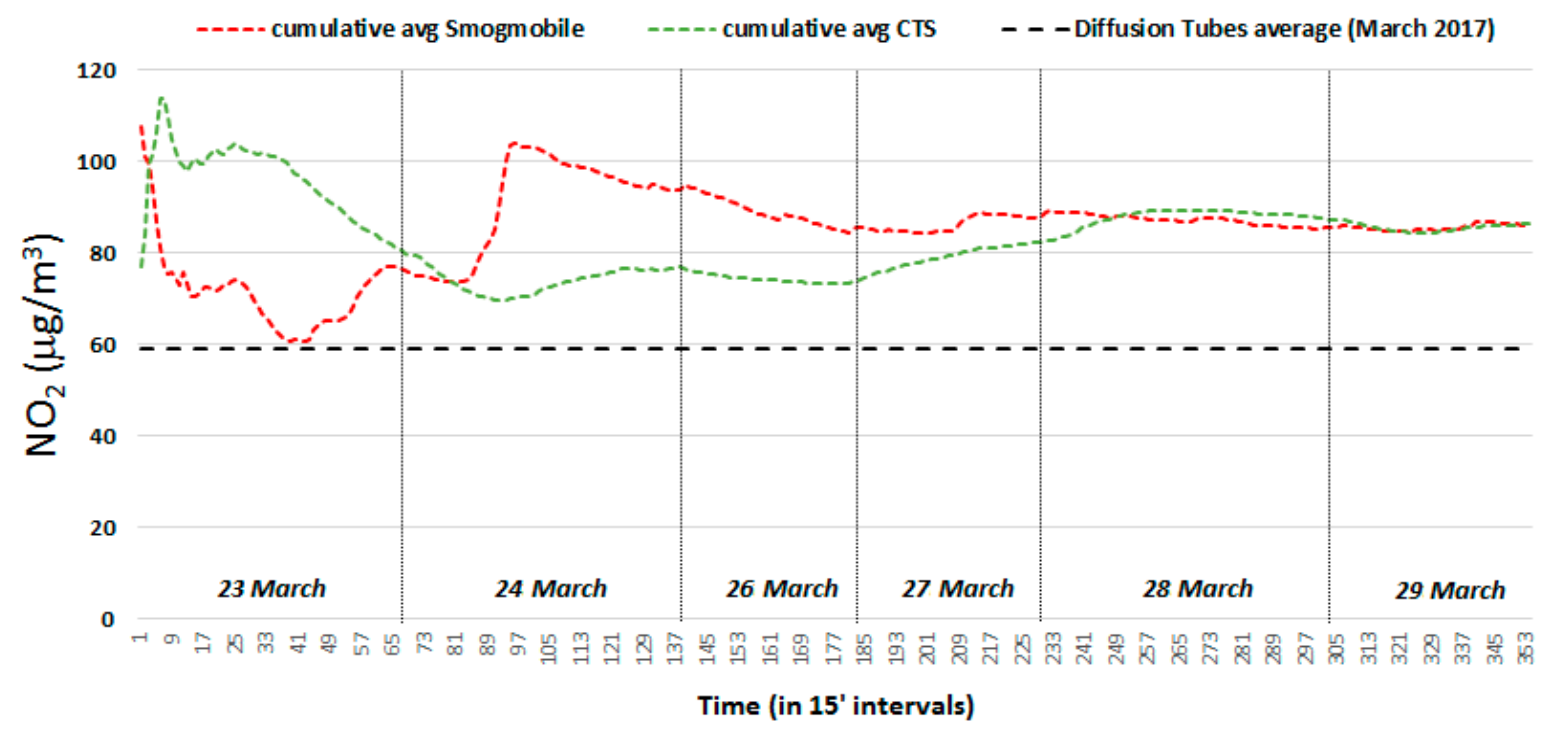

Figure 8. Cumulative average CMS (5-days), Smogmobile (5-days) and Diffusion Tube (Monthly) $\mathrm{NO}_{2}$ concentrations, $\mu \mathrm{g} / \mathrm{m}^{3}$ (Survey Period, March 2017).

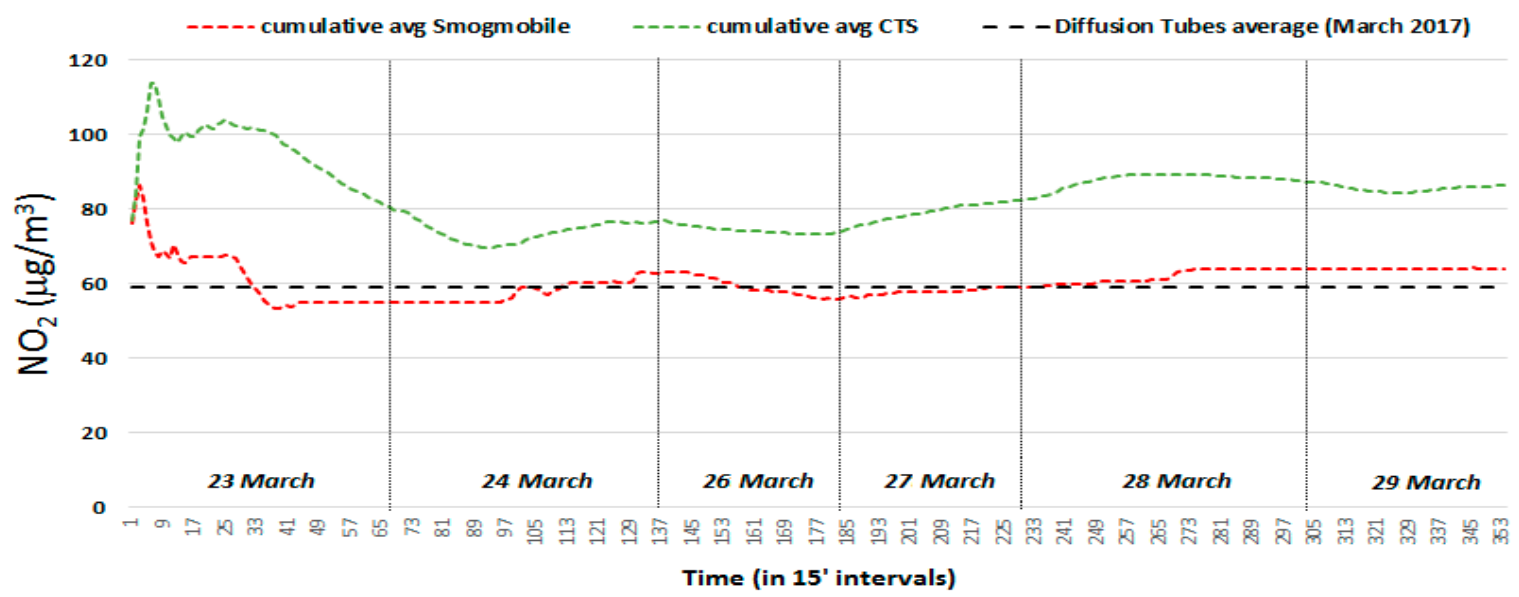

Figure 9. Cumulative average CMS (5-days), Smogmobile (excluding car park monitoring data, 5-day data) and Diffusion Tube (Monthly) $\mathrm{NO}_{2}$ concentrations, $\mu \mathrm{g} / \mathrm{m}^{3}$ (Survey Period, March 2017).

In Figure 8, the cumulative average CMS and Smogmobile concentrations tend to stabilise and converge, at the beginning of 28 March 2017, close to a value of approximately $86 \mu \mathrm{g} / \mathrm{m}^{3}$. This initial result indicates that the Smogmobile is capable of representing the average concentration across the City area, assuming that the CMS are considered to be broadly representative of air quality levels across the City.

However, when looking at Figure 9, where the stationary carpark measurements have been excluded from the analysis, the results are greatly different. Almost immediately, after few hours of mobile monitoring, the cumulative average Smogmobile $\mathrm{NO}_{2}$ concentration tends to stabilise around a value of $60 \mu \mathrm{g} / \mathrm{m}^{3}$, which is the same average value obtained using the concentrations reported for March 2017 by 48 diffusion tubes $\left(59.5 \mu \mathrm{g} / \mathrm{m}^{3}\right)$ spread across the CoL area. 
The analysis performed and its results pose some interesting questions in terms of the most appropriate duration of a mobile campaign and what periods of the year should be targeted, but fundamentally it opens up the possibility for the Smogmobile approach to be a potential alternative to, or to complement, traditional static methods (such as CMS and DT). However, the limited duration of the Smogmobile monitoring campaign in this study presents a serious limitation in terms of the accuracy of the statistical results; hence, a longer monitoring campaign, possibly split between two or even three periods of the year, would be advisable to capture both seasonal variations and to give more statistical robustness to the results and findings.

\subsection{Comparative Analysis Smogmobile, CMS, and DTs}

Based on the density plot analysis presented in Section 3.1 and considering the $200 \mathrm{~m}$ cell/grid network identified, by taking the three cells where the CMS are located and using the same ID reference to obtain the average $\mathrm{NO}_{2}$ concentration of the Smogmobile data points and diffusion tubes falling within those cells, a comparative analysis between Smogmobile, CMS, and diffusion tube average concentrations was carried out (see Figure 10).

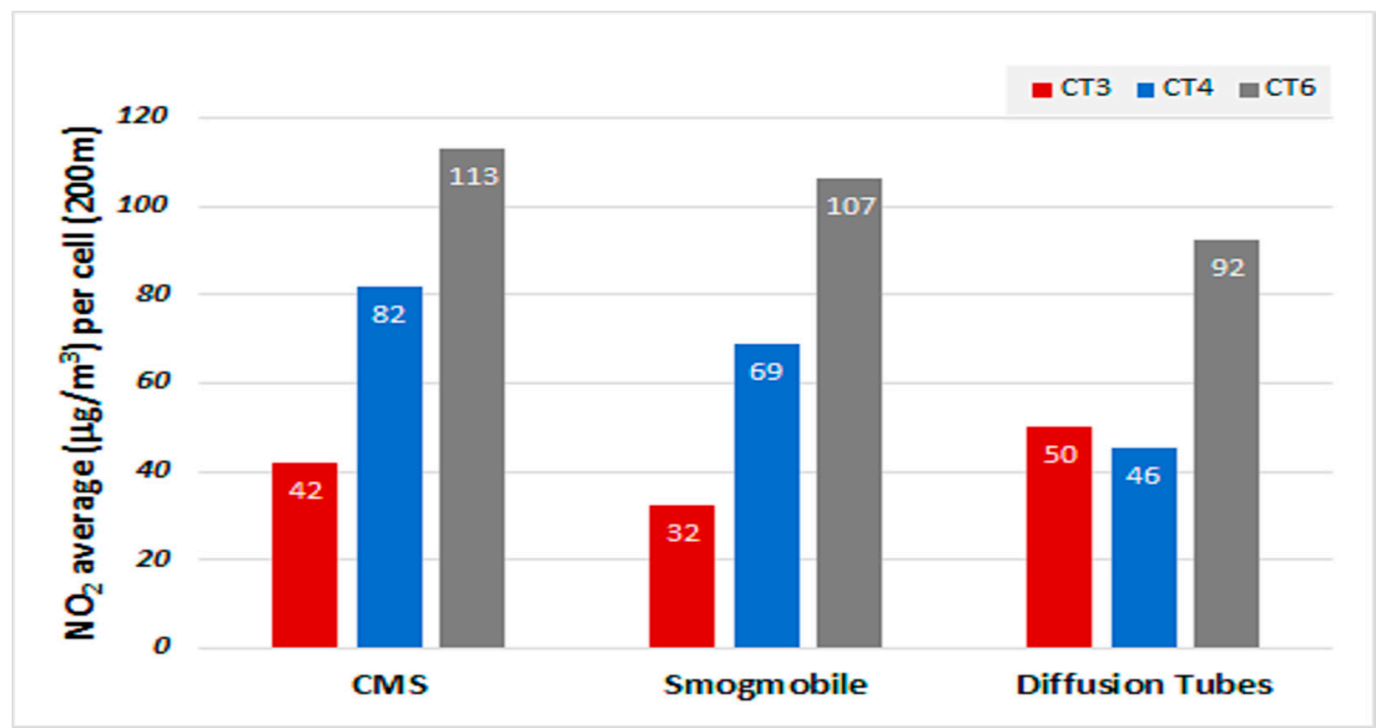

Figure 10. Comparative analysis of average $\mathrm{NO}_{2}$ concentrations between Smogmobile and CoL monitoring systems (CMS).

As can be observed, the Smogmobile average $\mathrm{NO}_{2}$ concentration is generally closer to the CMS than the diffusion tubes. For CT3 (Sir John Cass School), which is classified as an urban background site, the average $\mathrm{NO}_{2}$ concentration of the Smogmobile is $10 \mu \mathrm{g} / \mathrm{m}^{3}$ lower than that of the CMS and within a $\pm 25 \%$ error, whilst the diffusion tube average concentration is $8 \mu \mathrm{g} / \mathrm{m}^{3}$ higher than that of the CMS.

For CT4, the Smogmobile average $\mathrm{NO}_{2}$ concentration is much closer (16\% lower) to the CMS average than the diffusion tube average (44\% lower). For CT6, the average Smogmobile $\mathrm{NO}_{2}$ concentration is very close (5\% lower) to the CMS average.

These results provide further confidence that mobile monitoring is a suitable alternative, or can complement, static sensors. However, it is important to stress the difference in the time scale of the average values used/presented. The diffusion tube values are based on a one-month period (March 2017) whilst for the Smogmobile and the CMS, measurement data are available for a five-day period only. A truly comparative study will require, again, a longer duration monitoring campaign. 


\section{Discussion and Conclusions}

The use of density plots of the Smogmobile $\mathrm{NO}_{2}$ measurement data using ArcGIS is a promising approach to represent the variability of air pollution concentrations $\left(\mathrm{NO}_{2}\right)$ across the City of London. For the scope of this project, only two different grid resolutions (100 m and $200 \mathrm{~m}$ grid square networks) were used. It is recognised that the choice of grid dimensions can go beyond the two resolutions chosen, although for grid squares smaller than $100 \mathrm{~m}$, it is recommended that a longer campaign duration (at least two weeks) be implemented and that a pre-designed/planned route of the Smogmobile is carried out. This is to reduce the number of cells with no measurement to a minimum.

The use of grid square density plots, when associated with multiple campaigns over a calendar year, presents advantages in understanding the spatial variability of pollutant (e.g., $\mathrm{NO}_{2}$ ) concentrations across a wider area.

The analysis of the time series has provided initial insights into the statistical significance of the Smogmobile measurements to represent longer duration pollutant concentration averages. Particularly when looking at the weekly average from the precision continuous monitoring stations (CT3, CT4, and CT6) and all of the Smogmobile data for the same time period, they match very well.

When considering only the Smogmobile data collected with the outside inlet and on the street, the cumulative average of the Smogmobile $\mathrm{NO}_{2}$ concentration tends to stabilise very quickly around the value of $60 \mu \mathrm{g} / \mathrm{m}^{3}$, which is extremely close to the average value obtained using the concentration reported for March 2017 by all available (48) diffusion tubes, spread across the CoL area.

However in the future, it is envisaged that higher resolution of data collection (secby-sec) will allow finer grid resolutions, which can be used to assess trends and impacts of air quality strategies and policies even at a local scale, as well as improve the statistical significance of the Smogmobile measurements in representing $\mathrm{NO}_{2}$ (and other pollutants) concentrations. Further, this study and its initial findings, together with the potential to increase data collection resolution pose some interesting questions in terms of:

- What is the most appropriate duration of a mobile campaign?

- What periods of the year should be targeted?

- Under which conditions and locations can the Smogmobile approach can be considered a potential alternative to, or simply complement, the traditional static monitoring methods?

Another interesting finding is that when comparing the full weekly average $\mathrm{NO}_{2}$ concentration (Figure 7) with the annual mean for the individual and combined CMS, the values are very close (within 10\%) except for CT6 where higher concentrations $\left(116 \mu \mathrm{g} / \mathrm{m}^{3}\right)$ were measured. This provides evidence that precision measurements, although made in a limited time period (one week), can be used as a good proxy of the annual average. This is envisaged to have the potential for two main innovative applications:

- A predictive method for Local Authorities to anticipate, in the order of months, potential annual exceedances enabling timely interventions;

- Spatial and temporal representations of air quality across large areas or entire cities by using mobile monitoring techniques such as the Smogmobile.

This study, as illustrated in Section 3, provides useful insight and an initial response to the research question posed initially by the CoL: "Is the Smogmobile a valid alternative to static monitoring across urban areas"?

In most cases, the mobile monitoring performed better than the indicative method (DT) and can offer the right flexibility at an affordable cost, providing interesting spatial insights as well as a method to identify, dynamically, the variation and changes in pollutant concentrations over time due to traffic and weather variability.

\section{Next Steps}

The results from this research provide further support of the potential future application of the mobile monitoring approach to monitor spatially (and possibly temporally) 
air pollutant concentrations across large urban areas and to develop more cost-effective methods to assess air quality strategies and low emissions initiatives. Further, a $500 \mathrm{~m}$ grid cell resolution should be considered.

Moreover, it is opinion of the authors that mobile monitoring could provide a costeffective solution to assess environmental impacts for short-term and/or post construction monitoring (e.g., roadworks, school run period, city events) as well as to assess/better quantify implications of urban shapes/weather spatially and to improve the Air Quality modelling validation capabilities.

Author Contributions: Conceptualization, F.G., J.F.-M. and R.C.; methodology, F.G., J.F.-M.; validation, F.G., J.F.-M.; formal analysis, F.G., J.F.-M.; investigation, F.G., J.F.-M.; resources, F.G., J.F.-M. and R.C.; data curation, F.G.; writing-original draft preparation, F.G., J.F.-M.; writing-review and editing, F.G., J.F.-M.; visualization, F.G., J.F.-M.; supervision, F.G., R.C.; project administration, F.G., R.C.; funding acquisition, J.F.-M. All authors have read and agreed to the published version of the manuscript.

Funding: The research carried out in this paper has been funded by the City of London Corporation.

Data Availability Statement: 3rd Party Data. Restrictions apply to the availability of these data. Data were obtained from City of London Corporations and are available from the author R.C. with the permission of the CoL corporations.

Acknowledgments: The authors want to thank Ryan Johnston, formerly of the CPC, who undertook the geospatial analysis presented.

Conflicts of Interest: The authors declare no conflict of interest.

\author{
Abbreviations \\ CMS Continuous Monitoring Stations (also named CT within the paper) \\ DT Diffusion Tubes \\ CoL City of London Corporation \\ $\mathrm{NO}_{2} \quad$ Nitrogen Dioxide
}

\title{
References
}

1. Meng, Q.Y.; Turpin, B.J.; Korn, L.; Weisel, C.P.; Morandi, M.; Colome, S.; Zhang, J.; Stock, T.; Spektor, D.; Winer, A.; et al. Influence of ambient (outdoor) sources on residential indoor and personal PM2.5 concentrations: Analyses of RIOPA data. J. Expo. Sci. Environ. Epidemiol. 2004, 15, 17-28. [CrossRef] [PubMed]

2. Van Roosbroeck, S.; Li, R.; Hoek, G.; Lebret, E.; Brunekreef, B.; Spiegelman, D. Traffic-related outdoor air pollution and respiratory symptoms in children: The impact of adjustment for exposure measurement error. Epidemiology 2008, 19, 409-416. [CrossRef] [PubMed]

3. Nagendra, S.S.; Yasa, P.R.; Mv, N.; Khadirnaikar, S.; Rani, P. Mobile monitoring of air pollution using low cost sensors to visualize spatio-temporal variation of pollutants at urban hotspots. Sustain. Cities Soc. 2019, 44, 520-535. [CrossRef]

4. Minet, L.; Gehr, R.; Hatzopoulou, M. Capturing the sensitivity of land-use regression models to short-term mobile monitoring campaigns using air pollution micro-sensors. Environ. Pollut. 2017, 230, 280-290. [CrossRef] [PubMed]

5. Suriano, D.; Prato, M.; Pfister, V.; Cassano, G.; Camporeale, G.; Dipinto, S.; Penza, M. Stationary and Mobile Low-Cost Gas Sensor-Systems for Air Quality Monitoring Applications. In Proceedings of the 4th Scientific Meeting EuNetAir 2015; Linkoping University: Linkoping, Sweden. Available online: https://www.ama-science.org/proceedings/details/2130 (accessed on 12 January 2021). [CrossRef]

6. Zappi, P.; Bales, E.; Park, J.; Griswold, W.; Rosing, T. The citisense air quality monitoring mobile sensor node. In Proceedings of the 11th ACM/IEEE Conference on Information Processing in Sensor Networks, Beijing, China, 16-19 April 2012. Available online: https://www.researchgate.net/publication/267861564_The_CitiSense_Air_Quality_Monitoring_Mobile_Sensor_Node (accessed on 12 January 2021).

7. Apte, J.S.; Messier, K.P.; Gani, S.; Brauer, M.; Kirchstetter, T.W.; Lunden, M.M.; Marshall, J.D.; Portier, C.J.; Vermeulen, R.C.; Hamburg, S.P. High-Resolution Air Pollution Mapping with Google Street View Cars: Exploiting Big Data. Environ. Sci. Technol. 2017, 51, 6999-7008. [CrossRef] [PubMed]

8. Lim, C.C.; Kim, H.; Vilcassim, M.J.R.; Thurston, G.D.; Gordon, T.; Chen, L.-C.; Lee, K.; Heimbinder, M.; Kim, S.-Y. Mapping urban air quality using mobile sampling with low-cost sensors and machine learning in Seoul, South Korea. Environ. Int. 2019, 131, 105022. [CrossRef] [PubMed] 
9. Gelb, J.; Apparicio, P. Modelling Cyclists' Multi-Exposure to Air and Noise Pollution with Low-Cost Sensors-The Case of Paris. Atmosphere 2020, 11, 422. [CrossRef]

10. Mead, M.I.; Popoola, O.; Stewart, G.; Landshoff, P.V.; Calleja, M.; Hayes, M.J.; Baldovi, J.; McLeod, M.; Hodgson, T.; Dicks, J.; et al. The use of electrochemical sensors for monitoring urban air quality in low-cost, high-density networks. Atmos. Environ. 2013, 70, 186-203. [CrossRef]

11. Snyder, E.G.; Watkins, T.H.; Solomon, P.A.; Thoma, E.D.; Williams, R.W.; Hagler, G.S.W.; Shelow, D.; Hindin, D.A.; Kilaru, V.J.; Preuss, P.W. The Changing Paradigm of Air Pollution Monitoring. Environ. Sci. Technol. 2013, 47, 11369-11377. [CrossRef] [PubMed]

12. Department for Environment, Food and Rural Affairs (DEFRA). Clean Air Strategy. Available online: https://assets.publishing. service.gov.uk/government/uploads/system/uploads/attachment_data/file/770715/clean-air-strategy-2019.pdf (accessed on 12 January 2021).

13. John, L.A. Air Pollution around Gloucestershire (20 June 2017); Enviro Technology Services Ltd.: London, UK, 2017. Available online: https:/ / glostext.gloucestershire.gov.uk/documents/s39657/Air\%20Quality\%20Around\%20Gloucestershire\%20Schools\% 20Report\%20FINAL\%20200617\%20ANNEX\%20A.pdf (accessed on 12 January 2021). 